\title{
africaOn the Personnel Utilization Model for Organizational Design
}

\author{
Charles Ofiabulu, Oliver Charles-Owaba \\ (Department of Industrial and Production Engineering, Faculty of Technology/ University of Ibadan Nigeria)
}

\begin{abstract}
One condition for high workers productivity is the availability of the right amount of work at the position and better utilization of the organization's human resources. Optimal organizational structure contains optimal number of positions hence the optimal number of organization's personnel. Organisational structure design problems have been formulated as that of maximizing personnel utilization subject to some constraints with a heuristics as solution procedures. The difficulty of verifying the effectiveness of such heuristics in producing optimal organization has created model acceptability problems. The objective of this study is to reformulate the personnel utilisation model for organization design as a dynamic programming model that guarantee optimal organizational structure with maximal personnel utilization. The model was applied to an existing organization. A methodology was also to be developed for assessing the effectiveness of existing heuristics
\end{abstract}

Keywords: - Organizational design, Dynamic Programming, Personnel utilization, Organisational Structure, Modelling.

\section{INTRODUCTION}

A business organisation has many aspects. Some of these are organisational behaviour, size and shape of the organisation, positions and sections, span of control per supervisory and management positions and number of decision hierarchies. Others include information and communication channels, quality and volume of work, performance evaluation, human resource management, interrelationships, operating cost, productivity, profitability and the structure. On close examination, it appears obvious that most of these aspects are governed by the organisational structure. For instance, the number and location of positions and sections; decision hierarchies, communication channels and the span of control are elements of organisational structure. In turn, these elements, individually and severally, determine the shape, the size, interrelationships, the volume of work and the organisational behaviour. Perhaps, it is for these reasons many researchers consider the structure of business organisation as one of the strongest determinants of corporate performance $[1,2,3,4,5,6,7,8,9]$. Organisational structure is defined as the framework by which positions/jobs, their hierarchy are identified, and the personnel working relations specified as well as coordinated $[6,10,11]$. Hence, the amount of work for a particular business, speed of information flow and, to some extent, the quality of decisions, depend on the structure of organisation. Other parameters that depend on the structure include number of personnel, the number of managers, supervisors and decision levels. It thus appears safe to assume that the cost of doing business, the quality of work, the speed of service to internal and external customers will be dictated by the physical structure of a business organisation. A wrong structure may therefore imply excessive labour force, which leads to redundancy at the work place. It may also mean inadequate number and calibre of personnel, which may translate into poor quality, and inadequate volume of corporate work. In either case, the productivity and profitability of the business suffers severely.

Clearly, the specification of the structure of a business organisation may require some scientific approach that guarantees the exact number and calibre of personnel as well as the overall flow pattern of information and authority. An approach of this type should minimise not only personnel redundancy and inadequacies, but also enhance quality and timely decisions; improve corporate productivity and profitability. Expressed differently, there seems to be a compelling need for a formal procedure for designing an organisational structure capable of enhancing corporate productivity and profitability.

One precondition for high productivity is the availability of the right amount of work for each position. One measure of this availability is human utilisation index, the percentage of time worker is actually doing his or her work. Charles-Owaba [12,2] formulated and solved the organisational design problem using the Operations Research paradigm. Human utilisation index, the compliment of personnel redundancy, was the objective function; the span of control, the number of management levels, number of managers/supervisors per level were the design variables while the number of the lowest cadre of personnel and human interaction dynamic factors were the design parameters. 
However, solution procedure being a heuristic, does not guarantee an optimal organisation structure. Associated with every heuristic is a problem of verifying model effectiveness and acceptance. The development of a solution procedure that guarantees optimal solution to the organisational design problem with the hope of enhancing the model's acceptability constitutes the problem of this study.

In searching for a solution procedure that guarantees optimality, we note that the objective functions and constraints are not linear and so cannot be handled with the simplex algorithm. Hence, only two general categories of approaches: explicit enumeration and implicit enumeration are available. The former serves no useful purpose when the design variables are continuous quantities. Besides, it is the most inefficient approach. Among the implicit enumeration techniques are integer programming, branch and bound and dynamic programming. Of these three, the last two are suitable for any type of mathematical problem. However, for problems with easily noticeable structures suggestive of stage-by-stage solution procedure, the dynamic programming solution approach is usually recommended [13]. In view of the hierarchical nature of organisation structure, the possibility of using the dynamic programming framework as the basis for solution will be investigated in this research work.

In particular, the problem here in is to formulate an organisational design problem in terms of known design variables; design parameters; shape, size and policy constraints and then evolve a solution procedure, which guarantees an optimal business organisational structure with maximum personnel utilization. The design variables used are number of level, number of managers and the span of control of managers. The design parameters are the human interaction dynamics factors, and the number of hours of work.

\subsection{Notation}

\section{NOTATIONS AND ASSUMPTIONS}

$A_{i j}$ :Number of hours per day put in by the worker at $j^{\text {th }}$ position of the $i^{\text {th }}$ level of the organisation in hours.

$\mathbf{H}_{\mathbf{i}}$ : The human utilisation function or model of the $i^{\text {th }}$ levels of an organisational structured.

HU: Human utilisation function or model of an organisational structure accumulated over $M$ levels of organisational structure.

$\mathrm{K}_{\mathrm{ij}}$ : The span of control is the number of subordinates at $(\mathrm{i}-1)^{\text {th }}$ level that reports directly to the boss at the $j^{\text {th }}$ position of the $i^{\text {th }}$ level of the organisation.

$\mathrm{L}_{\mathrm{ij}}$ : $\quad$ This is the average number of cases in for the attention of decision maker/boss at $\mathrm{j}^{\text {th }}$ position of the $i^{\text {th }}$ level of the organisation.

$\overline{\mathrm{L}}_{\mathrm{ij}}$. This is the average number of cases that waited for the attention of decision maker/boss at $\mathrm{j}$ th position of the $i^{\text {th }}$ level of the organisation during the working hours.

$\mathrm{M}$ : The highest level of the entire organisation for which $\mathrm{N}_{\mathrm{i}}=1$

$\mathrm{N}_{\mathrm{ij}}$. This is the number of positions of the $\mathrm{j}^{\text {th }}$ type at the $\mathrm{i}^{\text {th }}$ level of the organisational structure. This may be number of functional or divisional (j) managers or supervisors at the $\mathrm{i}^{\text {th }}$ level of the organisation $\mathrm{i}=0,1$, $2, \mathrm{M}$

$\mathrm{N}_{0 \mathrm{j}}$. Number of operation positions of $\mathrm{j}^{\text {th }}$ type at the $0^{\text {th }}$ level of the organisation

NL: Number of management levels of the entire organisational structure

NM: This is the number of positions at levels 2 and above of the organisational structure

NS: Number of first level managers or supervisors of the organisational structure

$\mathbf{S}$ : is the total number of positions of the whole organisational structure (organisational Size).

SC: Average Span of control of managers is the number of subordinates per level.

$\mathbf{S}_{\mathbf{0}}$ : Operation position size of the organisation

$\mathrm{W}_{\mathrm{ij}}$ : This is the average waiting time of cases (from subordinate and the boss's superior) that came for the attention of the boss at the $\mathrm{j}^{\text {th }}$ position of the $\mathrm{i}^{\text {th }}$ level of the organisation. 
$\mu_{\mathrm{ij}}$ : This is the rate at which the boss at $\mathrm{j}^{\text {th }}$ position and $\mathrm{i}^{\text {th }}$ level attend to cases that came for his attention.

$\rho_{\mathrm{ij}}$ : This is ratio of the cases' arrival rate to the service rate of cases for the boss at $\mathrm{j}^{\text {th }}$ position and $\mathrm{i}^{\text {th }}$ level. This is the measure of information traffic intensity between each boss at $\mathrm{j}^{\text {th }}$ position of the $\mathrm{i}^{\text {th }}$ level and his subordinates a $(\mathrm{i}-1)^{\text {th }}$ levels.

$A_{i}$. Number of Hours worked per day by each worker at the $i^{\text {th }}$ level of a fair structured organisation in hours.

F: Human utilisation function or model of a fair structured organisation accumulated over $M$ levels of the organisation.

$\mathrm{K}_{\mathrm{i}}$.Span of control is the number of subordinates at $i-1^{\text {th }}$ level that reports directly to each boss at the $\mathrm{i}^{\text {th }}$ level of a fair structured organisation.

$\mathrm{L}_{\mathrm{i}}$ : This is the average number of cases that came for the attention of each decision maker/boss at the $i^{\text {th }}$ level of a fair structured organisation.

$\overline{\mathrm{L}}_{\mathrm{i}}$ : This is the average number of cases that waited for the attention of a decision maker/boss at the $\mathrm{i}^{\text {th }}$ level of a fair structured organisation.

$\mathrm{N}_{0}$ : This is the number of operation position in of a fair structured organisation .

$\mathrm{N}_{\mathrm{i}}$. This is the number of positions at the $\mathrm{i}^{\text {th }}$ level of a fair structured organisation $\mathrm{i}=1,2, ., ., \mathrm{M}$.

$\mathrm{W}_{\mathrm{i}}$ : This is the average waiting time of cases from subordinate and the boss's superior at each boss's position at the $i^{\text {th }}$ level of a fair structured organisation .

$\rho_{\mathrm{i}}$ : This is the measure of information traffic intensity between each boss at $i^{\text {th }}$ level and his subordinates at $(i-1)^{\text {th }}$ levels of a fair structured organisation .

$\mu_{\mathrm{i}}$. This is the rate at which each boss at $\mathrm{i}^{\text {th }}$ level of a fair structured organisation attends to cases that came for his attention.

\subsection{Assumptions}

1. Every employee is of normal health, highly motivated and at least, has one job to perform in the organisation;

2. The chance that personnel in a work unit will work most harmoniously is highest when the authority and responsibility to control the activities of the unit is assigned to one and only one boss at any given moment;

3. Standard workload (that is suitable for the position) and not maximum possible workload is assigned to every staff;

4. The organisation is a non-fully automated business organisation.

5. It is a personnel-personnel or personnel-machine interaction, stochastic and dynamic decision and operation work system;

6. The workload of a boss (superior) at decision centre is proportional to his/her span of control ( $\left.\mathrm{K}_{\mathrm{ij}}\right)$;

7. Requests, response to directives, situational reporting, classifications, authorizations, counselling are features of superior-subordinate relationships;

8. Arrival of cases for and departure from the boss are stochastic events; which follows (FIFO) First In, First Out queue discipline;

9. The superior is experienced enough to handle a decision centre. Otherwise, there will be a large heap of cases at every moment;

10. Data for parameter estimation are collected from the interaction stochastic and dynamic system, when it has passed from the transient to a steady state;

11. The time a case leaves its location and travels to the superior's desk is negligible. 


\section{HUMAN UTILIZATION MODEL OF ORGANISATIONAL DESIGN}

\subsection{Human utilisation Function}

An organisational structure consists of $\mathrm{j}=1,2,3, \ldots, \mathrm{J}$ types of positions at every $\mathrm{i}=1,2,3, \ldots, \mathrm{M}$ levels of the organisation. For $\mathrm{i}=0$, it is the level for the lowest cadre of workers; $\mathrm{i}=1$, it is the supervisory level; $\mathrm{i}$ $>1$, it is pure decision position as depicted in Fig 1. Consider a work unit (shown in Fig. 1) with a boss at the $j^{\text {th }}$ position of the $\mathrm{i}^{\text {th }}$ level and with $\mathrm{K}_{\mathrm{ij}}$ span of control (number of subordinates). The boss can be viewed as a server in a queuing system with finite source $\mathrm{K}_{\mathrm{ij}}$ (subordinates) of jobs or cases such as problems, clarifications, instructions, directives, information and so on.

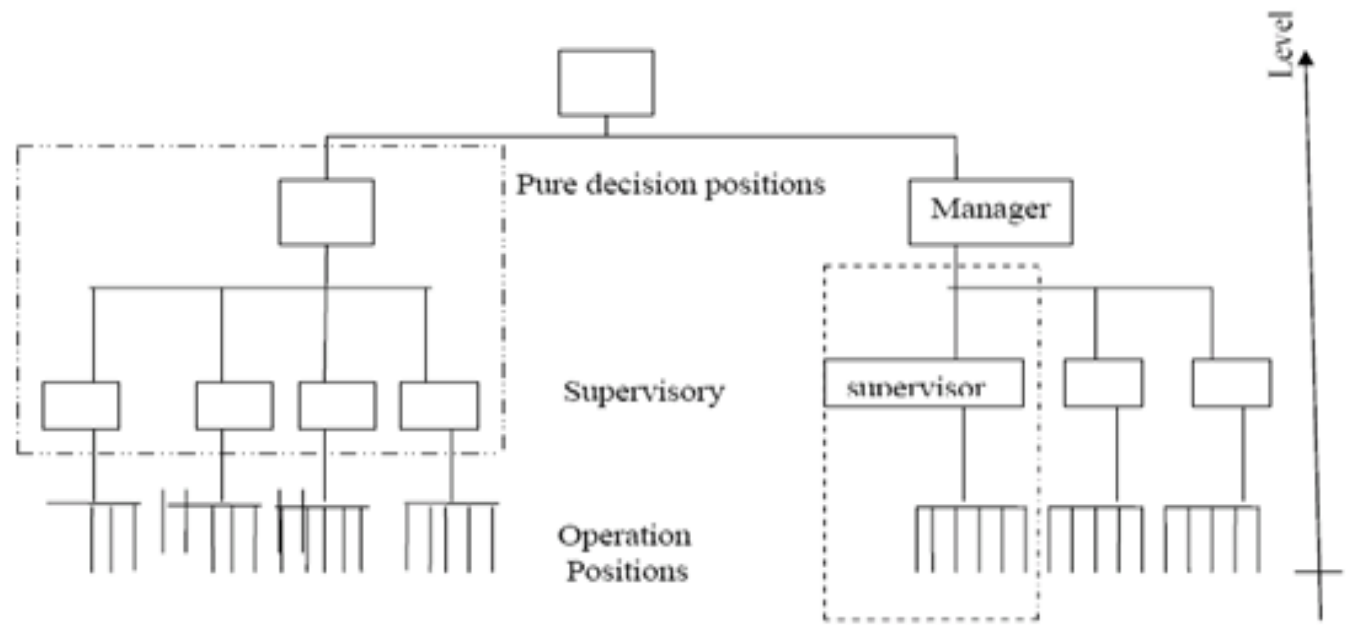

Figure 1 Organisational work units

For such organisational structure, the Human utilization index $[2,12]$ in the work unit with the boss at the $\mathrm{i}^{\text {th }}$ level $\mathrm{j}^{\text {th }}$ category of work and subordinates $\mathrm{K}_{\mathrm{ij}}$ is $\mathrm{H}_{\mathrm{ij}}$

$$
H_{i j}=\frac{L_{i j}\left(A_{i j}-W_{i j}\right)+\left(K_{i j}-L_{i j}\right) A_{i j}+\left(1-P_{i j}\right) A_{i j}}{A_{i j}\left(K_{i j}+1\right)}
$$

Where:

- $\mathrm{W}_{\mathrm{ij}} \leq \mathrm{A}_{\mathrm{ij}}$

- $\mathrm{L}_{\mathrm{ij}}\left(\mathrm{A}_{\mathrm{ij}}-\mathrm{W}_{\mathrm{ij}}\right)$ : Average daily man-hours actually spent working by the subordinates who consulted the boss for information or other reasons.

- $\mathrm{A}_{\mathrm{ij}}\left(\mathrm{K}_{\mathrm{ij}}-\mathrm{L}_{\mathrm{ij}}\right)$ : Daily man - hours actually spent working by those subordinates who have no reasons to seek information from the boss;

- $\mathrm{A}_{\mathrm{ij}}\left(1-\mathrm{P}_{\mathrm{ij}}\right)$ : Daily man-hours actually spent working by the occupier of $\mathrm{j}^{\text {th }}$ decision centre of the $i^{\text {th }}$ level; and

- $\mathrm{A}_{\mathrm{ij}}\left(\mathrm{K}_{\mathrm{ij}}+1\right)$ : Daily man-hours scheduled for work by subordinates and superior in the work unit at the $\mathrm{j}^{\text {th }}$ position of the $\mathrm{i}^{\text {th }}$ level.

Factorizing and applying the fair structure assumption, we have the personnel utilisation index at $\mathrm{i}^{\text {th }}$ level of organisation

$$
H_{i j}=1-\frac{\left(L_{i j} W_{i j}+P_{i j} A_{i j}\right)}{A_{i j}\left(K_{i j}+1\right)}
$$

The human utilisation index of the $\mathrm{i}^{\text {th }}$ of organisation $\mathrm{H}_{\mathrm{i}}$ is obtained by summing for the positions for all the levels. 
$H_{i}=\frac{\sum_{j=1}^{N_{i}}\left(N_{i j} H_{i j}\right)}{\sum_{j=1}^{N_{i}} N_{i j}}=\frac{\sum_{j=1}^{N_{i}}\left(N_{i j}\left(1-\frac{\left(L_{i j} W_{i j}+P_{i j} A_{i j}\right)}{A_{i j}\left(K_{i j}+1\right)}\right)\right)}{\sum_{j=1}^{N_{i}} N_{i j}}$

$H=\sum_{i=1}^{M}\left(\frac{\sum_{j=1}^{N_{i}}\left(N_{i j}\left(1-\frac{\left(L_{i j} W_{i j}+P_{i j} A_{i j}\right)}{A_{i j}\left(K_{i j}+1\right)}\right)\right)}{\sum_{j=1}^{N_{i}} N_{i j}}\right)$

From the queuing analysis $[14,15]$, the probability that no case is in the system of a server and a finite customer source Kij at stability $\mathrm{P}_{(\mathrm{ij})}$ is

A. The probability that no case require the attention of the boss (the boss is idle) is

$P_{i j}=\left[\sum_{n=0}^{1} C_{n}^{K_{i j}+2} n ! \rho_{i j}^{n}+\sum_{n=2}^{K_{i j}+2} C_{n}^{K_{i j}+2} n ! \rho_{i j}^{n}\right]^{-1}$

B. The average number of cases which came during the considered time $A_{\mathrm{ij}}$ to receive the attention of the boss at position $\mathrm{j}$ of $\mathrm{i}^{\text {th }}$ level is given by

$L_{i j}=\sum_{n=0}^{K_{i j}+2} n P_{(n) i j}=\sum_{n=0}^{K_{i j}+2} C_{n}^{K_{i j}+2} n ! \rho_{i j} P_{i j}$

C. The average number of cases which waited during the considered time $\mathrm{A}_{\mathrm{ij}}$ to receive the attention of the boss at position $\mathrm{j}$ of $\mathrm{i}^{\text {th }}$ level is

D. $\bar{L}_{i j}=\sum_{n=2}^{K_{i j}+2}(n-1) C_{n}^{K_{i j}+2} n ! \rho_{i j} P_{i j}$

E. The average waiting time of cases at position of the boss is

$\mathrm{W}_{\mathrm{ij}}=\frac{\mathrm{L}_{\mathrm{ij}}}{\lambda_{\mathrm{ij}}}=\frac{\mathrm{L}_{\mathrm{ij}}}{\lambda_{\mathrm{ij}}\left(\mathrm{K}_{\mathrm{ij}}-\mathrm{L}_{\mathrm{ij}}\right)}=\frac{\left(\overline{\mathrm{L}}_{\mathrm{ij}}+1-\mathrm{P}_{\mathrm{ij}}\right)}{\left(1-\mathrm{P}_{\mathrm{ij}}\right) \mu_{\mathrm{ij}}}$.

Substituting the expressions for the variables $\mathrm{P}_{\mathrm{ij}}, \mathrm{L}_{\mathrm{ij}}$ and $\mathrm{W}_{\mathrm{ij}}$ from equations 4,5 , and 6 respectively into equation 8 we have:

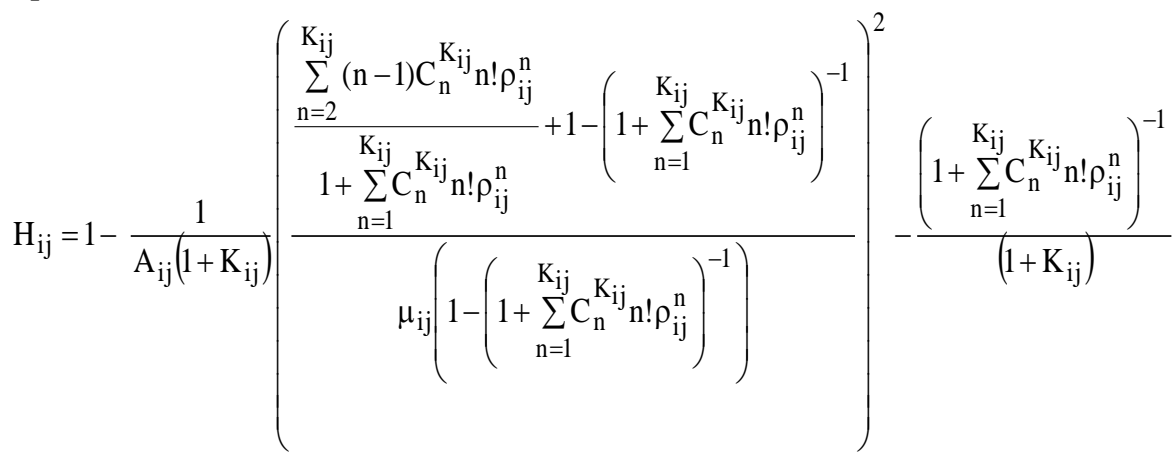

$\mathrm{H}_{\mathrm{ij}}=\mathrm{f}\left(\mathrm{K}_{\mathrm{i}}, \mathrm{N}_{\mathrm{i}}, \phi_{\mathrm{h}},\right)$

In a fair structured organisation, we assume that managers or and supervisors at the same level of organization carry fairly the same level of responsibilities and work load. This implies that the following holds:

$K_{i 1}=K_{i 2}=K_{i j}=K_{i}$, and $\mu_{\mathrm{i} 1}=\mu_{\mathrm{i} 2}=\mu_{\mathrm{ij}}=\mu_{\mathrm{i}}$,

Also $\lambda_{i 1}=\lambda_{i 2}=\lambda_{i j}=\lambda_{i}$, and $b_{i 1}=b_{i 2}=b_{i j}=b_{i}$ 
Hence, the $\mathrm{i}^{\text {th }}$ level and $(\mathrm{i}-1)^{\text {th }}$ level of the organisation are related thus:

$\frac{\mathrm{N}_{\mathrm{i}-1}}{\mathrm{~K}_{\mathrm{ij}}}=\sum_{\mathrm{j}=1}^{\mathrm{Ni}} \mathrm{j}=\mathrm{Ni}$

The human utilisation index of work unit at the $\mathrm{i}^{\text {th }}$ level $\mathrm{H}_{\mathrm{ij}}=\mathrm{H}_{\mathrm{i}}$ and the human utilisation index of the organisational structure with M levels is $\mathrm{HU}$

$\mathrm{HU}=\mathrm{F}=\frac{\sum_{\mathrm{i}=1}^{\mathrm{M}} \mathrm{N}_{\mathrm{i}} \mathrm{H}_{\mathrm{i}}\left(\mathrm{K}_{\mathrm{i}}, \mathrm{N}_{\mathrm{i}}, \phi_{\mathrm{i}}\right)}{\sum_{\mathrm{i}=1}^{\mathrm{M}} \mathrm{N}_{\mathrm{i}}}$.

The human utilisation of an organisation structure is function of the parameters: consultation rate of the of subordinates at level $\mathrm{i}, \lambda_{\mathrm{i}}$; ; attendance rate at level $\mathrm{i}, \mu_{\mathrm{i}}$; number of operating positions $\mathrm{N}_{0}$ and variables: number of positions at the level $\mathrm{N}_{\mathrm{i}}$; the span of control $\mathrm{K}_{\mathrm{i}}$ and the number of level $\mathrm{M}$ of the organisation.

3.2 The organisational design problem

We defined the organisational design problem as:

Maximise $H\left(K_{i j}, N_{i}, M, \phi_{h}\right)=\frac{\sum_{i=1}^{M} \sum_{j=1}^{N_{i}} H_{i j}\left(K_{i j} \phi_{h}\right)}{\sum_{i=1}^{M} N_{i}}$

Subject to:

$\sum_{j=1}^{N_{i j}} K_{i j}=N_{i-1, j}$

$\mathrm{N}_{\mathrm{M}}=1$

$\mathrm{K}_{\mathrm{ij}}, \mathrm{N}, \mathrm{M}, \geq 1$

Where $\phi_{\mathbf{h}}$ is the $\operatorname{set}\left\{\boldsymbol{\lambda}_{\mathbf{i j}}, \boldsymbol{\mu}_{\mathbf{i j}}, \mathbf{N}_{\mathbf{0}}\right\}$ are the design parameters while $\mathrm{K}_{\mathrm{ij}}$, the span of control; $\mathrm{N}_{\mathrm{i}}$, the number of personnel at level $\mathrm{i}$ and $\mathrm{M}$, the number of decision levels are the design variables.

\subsection{The Heuristic Solution}

The heuristics solution approach developed in [12,2] is as outlined below:

Step 0 Determine the total number of operation positions $\mathrm{N}_{0}$, of a particular organisation and the available hours of work A

Step 1 Set the level of organisation $\mathrm{i}=1$

Step 2: Determine the $\mu_{\mathrm{i}}$ rate at which the boss attends to the subordinates and the rate at which the subordinates consults the boss, $\lambda_{\mathrm{i}}$, for the level $i$

Step 3a: Substitute $\mathrm{N}_{\mathrm{i}}$ with $\frac{\mathrm{N}_{\mathrm{i}-1}}{\mathrm{~K}_{\mathrm{i}}}$ in $\mathrm{H}_{\mathrm{i}}$ functions

Step 3b: Compute the values of $\mathrm{H}_{\mathrm{i}}$ functions of $K_{i j}$ values $2,3, \ldots \ldots N_{0}$ and determine the $K_{i j}$ for which the value of $\mathrm{H}_{\mathrm{i}}$ functions is maximum and for which $W_{i j}$ is less than $A_{i j}$ and denote it as $K_{i j}^{*}$

Step 4: Determine the number of positions $\mathrm{N}_{\mathrm{i}}$ at level $i \mathrm{~N}_{\mathrm{I}}=\frac{\mathrm{N}_{\mathrm{i}-1}}{\mathrm{~K}_{\mathrm{ij}}^{*}}$

Step 5: If $N_{i}=1$ Go to Step 7

Step 6: Set $i=i+1$ and go to step 2

Step 7: $\quad N_{M}=\frac{N_{M-1}}{K_{M j}^{*}} \mathrm{~N}_{\mathrm{M}}=1, N_{M-1}=\frac{N_{M-2}}{K_{M-1, j}^{*}}, \ldots \ldots \ldots \ldots \ldots \ldots . \cdots \cdots N_{1}=\frac{N_{0}}{K_{1 j}^{*}}$ 


\section{Step 8: END}

\section{DYNAMIC PROGRAMMING (DP) APPROACH MAXIMIZATION OF HUMAN}

\section{UTILISATION}

The general dynamic Programming approach to problems is to optimize in stages.

We denote the level of the organisation as the stages with the span of control $K_{i}$ as the stage variables and the number of positions at the level $\mathrm{N}_{\mathrm{i}}$ as the stage decision variables.

The equation relating a stage to another is

$\mathrm{F}_{\mathrm{i}}\left(\mathrm{i}, \mathrm{N}_{\mathrm{i}}, \mathrm{K}_{\mathrm{i}}, \theta_{1}\right)=\mathrm{f}_{\mathrm{i}}\left(\mathrm{i}, \mathrm{N}_{\mathrm{i}}, \mathrm{K}_{\mathrm{i},} \theta_{1}\right)+\mathrm{F}_{\mathrm{i}-1}^{*}\left(\mathrm{i}-1, \mathrm{~N}_{\mathrm{i}-1}^{*}, \mathrm{~K}_{\mathrm{i}-1}^{*}, \theta_{1-1}\right)$ Where

- $\mathrm{F}_{\mathrm{i}}\left(\mathrm{i}, \mathrm{N}_{\mathrm{i}}, \mathrm{K}_{\mathrm{i}}, \theta_{1}\right)$ is the value of the personnel utilisation index up to the level $\mathrm{i}^{\mathrm{th}}$ of the organisation for any pairs of feasible of $\mathrm{N}_{\mathrm{i}}$ and $\mathrm{K}_{\mathrm{i}}$ (i.e. all $\mathrm{N}_{\mathrm{i}}$ and $\mathrm{K}_{\mathrm{i}}$ for which $\mathrm{N}_{\mathrm{i}} \mathrm{K}_{\mathrm{i}} \cong \mathrm{N}_{\mathrm{i}-1}$ and $\mathrm{W}_{\mathrm{ij}}\left(\mathrm{N}_{\mathrm{i}}, \mathrm{K}_{\mathrm{i}}, \theta_{\mathrm{i}}\right) \leq \mathrm{A}_{\mathrm{i}}$ )

- $\mathrm{f}_{\mathrm{i}}\left(\mathrm{i}, \mathrm{N}_{\mathrm{i}}, \mathrm{K}_{\mathrm{i}}, \theta_{1}\right)$ is the value of the criterion function personnel utilisation index at the $\mathrm{i}^{\text {th }}$ level of the organisation, for any pair of feasible of $\mathrm{N}_{\mathrm{i}}$ and $\mathrm{K}_{\mathrm{i}}$ ( i.e. $\mathrm{N}_{\mathrm{i}} \mathrm{K}_{\mathrm{i}}=\mathrm{N}_{\mathrm{i}-1}$ and $\mathrm{W}_{\mathrm{ij}}\left(\mathrm{N}_{\mathrm{i}}, \mathrm{K}_{\mathrm{i}}, \theta_{\mathrm{i}}\right) \leq \mathrm{A}_{\mathrm{i}}$ )

- $\mathrm{F}_{\mathrm{i}-1}^{*}\left(\mathrm{i}-1, \mathrm{~N}_{\mathrm{i}-1}^{*}, \mathrm{~K}_{\mathrm{i}-1}^{*}, \theta_{1-1}\right)$ is the maximum value of the function at the stage $\mathrm{i}-1$

- $\mathrm{N}_{\mathrm{i}-1}^{*}, \mathrm{~K}_{\mathrm{i}-1}^{*}$, are the optimal values at the $\mathbf{i}-1$ stage of number of positions and span of control respectively

$\bullet$

\subsection{The Dynamic Programming Algorithm}

Step 1: Set $\mathrm{i}=1$ Determine the feasible pairs of $\mathrm{N}_{\mathrm{ij}}$ and $\mathrm{K}_{\mathrm{ij}}$ for which the following holds: $\mathrm{N}_{\mathrm{O}}-\mathrm{DX} \leq \mathrm{N}_{1} \mathrm{~K}_{1} \leq \mathrm{N}_{\mathrm{O}}+\mathrm{DX} \quad \forall \quad \mathrm{K}_{1}=2,3,4, \ldots . . \mathrm{N}_{\mathrm{O}}$

Step:2 For each pair of $\mathrm{N}_{1}$ and $\mathrm{K}_{1}$ determined as feasible in step2 Compute the waiting time $\mathrm{W}_{1}\left(\mathrm{~N}_{1}, \mathrm{~K}_{1}, \theta_{1}\right)$ using equation 8. If waiting time $\mathrm{W}_{1}\left(\mathrm{~N}_{\mathrm{i}}, \mathrm{K}_{\mathrm{i}}, \theta_{\mathrm{i}}\right)>\mathrm{A}_{1}$, Discard the pair of $\mathrm{N}_{\mathrm{i}}$ and $\mathrm{K}_{\mathrm{ij}}$ otherwise, compute the Human utilisation $\mathbf{f}_{\mathbf{i}}=\mathbf{H}_{\mathbf{i}}\left(\mathbf{N}_{\mathbf{i}}, \mathbf{K}_{\mathbf{i}}, \boldsymbol{\phi}_{\mathbf{i}}\right)$ for all the feasible pairs of $\mathbf{N}_{\mathbf{i}}$ and $\mathrm{K}_{\mathbf{i}}$ using equation 9.

Step 3 For every $\mathbf{N}_{\mathbf{i}}$ with the $\mathbf{f}_{\mathbf{i}}\left(\mathbf{N}_{\mathbf{i}}, \mathbf{K}_{\mathbf{i}}, \phi_{\mathbf{i}}\right)$ determined in step 3 , Calculate the $F_{i}\left(N_{i}, K_{i}, \phi_{1}\right)=\frac{f_{i}\left(N_{i}, K_{i}, \phi_{1}\right) N_{i}+F_{i-1}^{*}\left(N_{i-1}^{*}, K_{i-1}^{*}, \phi_{1-1}\right) N_{i-1}}{N_{i}+N_{i-1}}$, Write out for every $N_{i}$ and all the $F_{i}\left(N_{i}, K_{i}, \phi_{1}\right)$ and $K_{i} S$ corresponding to each $F_{i}\left(N_{i}, K_{i}, \phi_{1}\right)$ Determine for every $N_{i}$ the maximum $\mathrm{F}_{\mathrm{i}}\left(\mathrm{N}_{\mathrm{i}}, \mathrm{K}_{\mathrm{i}}, \phi_{1}\right)$ and denote it as $\mathrm{F}_{1}^{*}\left(\mathrm{~N}_{\mathrm{i}}, \mathrm{K}_{1}^{*}, \phi_{1}\right)$ Note also the value of $\mathrm{K}_{1}{ }^{*}$ corresponding to the $F_{1}^{*}\left(N_{i}, K_{1}^{*}, \theta_{1}\right)$

Step; 4 Determine the maximum $\mathrm{F}_{1}^{*}\left(\mathrm{~N}_{\mathrm{i}}, \mathrm{K}_{1}^{*}, \phi_{1}\right)$ for all the $\mathrm{N}_{\mathrm{i}}$ at the $\mathrm{i}$ stage and denote it as $\mathrm{F}_{1}^{* *}\left(\mathrm{~N}_{\mathrm{i}}, \mathrm{K}_{1}^{*}, \phi_{1}\right)$ If $\mathrm{F}_{1}^{* *}\left(\mathrm{i}, \mathrm{N}_{\mathrm{i}}, \mathrm{K}_{1}^{*}, \phi_{1}\right)$ corresponds to $\mathrm{N}_{\mathrm{i}}=1=1$, Go to step 10. If $\mathrm{F}_{1}^{* *}\left(\mathrm{~N}_{\mathrm{i}}, \mathrm{K}_{1}^{*}, \phi_{1}\right)$ corresponds to $\mathrm{N}_{\mathrm{i}}=2$ or $\mathrm{N}_{\mathrm{i}}=3$ Note $\mathrm{F}_{1}^{* *}\left(\mathrm{i}, \mathrm{N}_{\mathrm{i}}, \mathrm{K}_{1}^{*}, \phi_{1}\right)$ for $\mathrm{N}_{\mathrm{i}}=1$ this stage as $\mathbf{L 3}^{*}\left(\mathrm{~N}_{\mathrm{i}-1 \mathrm{j}}\right)$ and note its $\mathrm{K}_{\mathrm{ij}}^{1}$ value corresponding to it.

Step: 6 Set $\mathrm{i}=\mathrm{i}+1$. Determine the feasible pairs of $\mathrm{Ni}$ and $\mathrm{K}_{\mathrm{ij}}$ for which relation $\mathrm{N}_{\mathrm{i}} \mathrm{K}_{\mathrm{i}} \in\left\{\mathrm{N}_{\mathrm{i}-1}\right\}$ and $\mathrm{W}_{\mathrm{i}}\left(\mathrm{N}_{\mathrm{i}}, \mathrm{K}_{\mathrm{i}}, \theta_{\mathrm{i}}\right) \leq \mathrm{A}_{1}$

Step: 7. Compute the human utilisation index using $f_{i}=H_{i}\left(i, N_{i}, K_{i}, \phi_{i}\right)$ for the pair of $N_{i}$ and $K_{i}$ using equation 9. Calculate $F_{i}\left(i, N_{i}, K_{i}, \phi_{1}\right)=\frac{f_{i}\left(i, N_{i}, K_{i}, \phi_{1}\right) N_{i}+F_{i-1}^{*}\left(i-1, N_{i-1}^{*}, K_{i-1}^{*}, \phi_{1-1}\right)}{N_{i}+N_{i-1}}$ Write out for every $\mathrm{N}_{\mathrm{i}}$, and all the $\mathrm{F}_{\mathrm{i}}\left(\mathrm{i}, \mathrm{N}_{\mathrm{i}}, \mathrm{K}_{\mathrm{i}}, \phi_{1}\right)$ and $\mathrm{K}_{\mathrm{i}} \mathrm{S}$ corresponding to each $\mathrm{F}_{\mathrm{i}}\left(\mathrm{i}, \mathrm{N}_{\mathrm{i}}, \mathrm{K}_{\mathrm{i}}, \phi_{1}\right)$ Determine for every $\mathrm{N}_{\mathrm{i}}$ the maximum $\mathrm{F}_{\mathrm{i}}\left(\mathrm{i}, \mathrm{N}_{\mathrm{i}}, \mathrm{K}_{\left.\mathrm{i}, \phi_{1}\right)}\right.$ and denote it as $\mathrm{F}_{\mathrm{i}}^{*}\left(\mathrm{i}, \mathrm{N}_{\mathrm{i}}, \mathrm{K}_{\mathrm{i}}, \phi_{1}\right)$ Note also the value of $\mathrm{K}_{1 \mathrm{j}}{ }^{*}$ 
corresponding to the $F_{1}^{*}\left(i, N_{i}, K_{1}^{*}, \theta_{1}\right)$ Determine the minimum $F_{i}^{*}\left(i, N_{i}, K_{i}, \phi_{1}\right)$ for all the $N_{i}$ at the $i$ stage and denote it as $\mathrm{F}_{1}^{* *}\left(\mathrm{i}, \mathrm{N}_{\mathrm{i}}, \mathrm{K}_{1}^{*}, \theta_{1}\right)$

Step:8 If the maximum of the $\mathrm{F}_{\mathrm{i}}^{*}\left(\mathrm{i}, \mathrm{N}_{\mathrm{i}}, \mathrm{K}_{\mathrm{i}}, \phi_{1}\right)$ for all $\mathrm{N}_{\mathrm{ij}}$ at this stage correspond to value for $\mathrm{Ni}=1$, go to step: 9. If the $\mathrm{F}_{1}^{* *}\left(\mathrm{i}, \mathrm{N}_{\mathrm{i}}, \mathrm{K}_{1}^{*}, \theta_{1}\right)$ maximum value of the $\mathrm{F}_{\mathrm{i}}^{*}\left(\mathrm{i}, \mathrm{N}_{\mathrm{i}}, \mathrm{K}_{\mathrm{i}}, \phi_{1}\right)$ for all $\mathrm{N}_{\mathrm{i}}$ at this stage occur at $N_{i}=2$ or $N_{i}=3$; Note $F_{i}^{*}\left(i, N_{i}, K_{i}, \phi_{1}\right)$ for $N_{i}=1$ at this stage as $L^{*}\left(N_{i-1, j}\right)$ and $K_{i j}$ corresponding to it as $\mathrm{K}_{\mathrm{ij}}^{1}$

Step:9 Go To Step:5

Step:10 . If $\mathrm{F}_{1}^{* *}\left(\mathrm{i}, \mathrm{N}_{\mathrm{i}}, \mathrm{K}_{1}^{*}, \theta_{1}\right)$ for $\mathrm{N}_{\mathrm{i}}=1$ is greater than $\mathrm{L}^{*}(\mathrm{~N} 1)$ ( if it exists) Go To step 11

Step:10 the value of $F_{1}^{* *}\left(i, N_{i}, K_{1}^{*}, \theta_{1}\right)$ for $N_{i}=1$ is the maximum human utilisation index $\quad \mathrm{i}-1$ is the number of levels $\mathrm{M}$

$$
\begin{aligned}
& \mathrm{N}_{\mathrm{i}}=\mathrm{N}_{\mathrm{M}}=1 \\
& \mathrm{~N}_{\mathrm{M}-1}=\mathrm{K}_{\mathrm{M}}^{*} \\
& \mathrm{~N}_{\mathrm{i}-1}=\mathrm{N}_{\mathrm{i}} \mathrm{K}_{\mathrm{i}} \\
& \ldots \ldots \ldots \ldots \ldots \\
& \mathrm{N}_{0}=\mathrm{K}_{1} \mathrm{~N}_{1}
\end{aligned}
$$

Step: $11 \mathrm{~F}=\mathrm{L} *\left(\mathrm{~N}_{\mathrm{i}-1}\right.$ is the maximum value of personnel utilisation

$\mathrm{i}-1$ is the number of level $\mathrm{M}$

$\mathrm{N}_{\mathrm{M}}=1$

$\mathrm{N}_{\mathrm{M}-1}=\mathrm{K}_{\mathrm{M}}^{*}$

$\mathrm{N}_{\mathrm{i}-1}=\mathrm{N}_{\mathrm{i}} \mathrm{K}_{\mathrm{i}}$

$$
\mathrm{N}_{0}=\mathrm{K}_{1} \mathrm{~N}_{1}
$$

Step:12 End

\section{Application}

We collected data on a manufacturing firm and determined the parameter values. TABLE 1 shows the parameter values and the existing organisational structure. The existing organizational structure has three departments with staff strength (organisational size) of 250. The decision positions, operation positions and number of organizational levels were 46, 204 and 6 respectively.

Table 1Existing organisational structure and Parameter values

\begin{tabular}{|l|l|l|l|l|l|}
\hline Level & hours & \multicolumn{2}{l|}{ Cases/ hour } & \multicolumn{2}{l|}{} \\
\hline $\mathrm{I}$ & $\mathrm{A}$ & $\lambda_{i}$ & $\mu$ & $\mathrm{Ni}$ & $\mathrm{Ki}$ \\
\hline 4 & 8 & $2 . .15$ & 2.5 & 1 & 4 \\
\hline 3 & 8 & 1.25 & 1.75 & 4 & 3 \\
\hline 2 & 8 & 1.33 & 3.378 & 12 & 2 \\
\hline 1 & 8 & 0.94 & 4.37 & 29 & 7 \\
\hline 0 & 8 & - & - & 204 & - \\
\hline
\end{tabular}

The organisational design problem defined in section 3,2, was solved with parameter values in TABLE 1. The organisational design problem was solved using both the proposed Dynamic Programming (DP) 
Algorithm and the existing heuristics methods. The organisational structures resulting from both methods in terms of levels, number of positions per level and span of control per level are shown in TABLE. TABLE 3 is a summary of the following organisational characteristics designed structure: Personnel Utilisation, Computation time, Number of management levels, Number of managers, Number of supervisors, Average span of control and Organizational size for the DP, the Heuristics and the existing structure.

Table 2 Designed organisational structures

\begin{tabular}{|l|l|l|l|l|}
\hline & \multicolumn{2}{l}{ DP } & \multicolumn{2}{l|}{ Heuristics } \\
\hline Level & $\mathrm{Ni}$ & $\mathrm{Ki}$ & $\mathrm{Ni}$ & $\mathrm{Ki}$ \\
\hline 4 & - & - & 1 & 2 \\
\hline 3 & 1 & 4 & 2 & 3 \\
\hline 2 & 4 & 4 & 6 & 4 \\
\hline 1 & 24 & 6 & 24 & 6 \\
\hline 0 & 145 & - & 145 & 145 \\
\hline $\mathrm{H}$ & 0.974 & & 0.957 & \\
\hline
\end{tabular}

Table 3.Organisational characteristics

\begin{tabular}{|l|l|l|l|l|}
\hline S/No & Organisational characteristics & DP Designed & $\begin{array}{l}\text { Heuristics } \\
\begin{array}{l}\text { Existing } \\
\text { - }\end{array}\end{array}$ & 0.974 \\
\hline 1. & Personnel Utilisation & 1.65 & 15.0 & - \\
\hline 2. & Computation time (s) & 3 & 4 & 4 \\
\hline 3. & Number of management level & 3 & 9 & 17 \\
\hline 4. & Number of managers & 5 & 24 & 29 \\
\hline 5. & Number of supervisors & 24 & 4.6 & 4 \\
\hline 6. & Average span of control & 5.6 & 178 & 250 \\
\hline 7. & Organization size & 178 & & \\
\hline
\end{tabular}

\subsection{Results and Discussion}

In the design criterion of maximizing the personnel utilization, the Dynamic programming (DP) design algorithm produce smaller organizational structures as evident in the results presented in TABLE 2 and 3 . The organizational Number of management level of the DP designed structure (3) was smaller than that of the heuristic-designed (4) for the cases studied. This observation also holds for the number of managers and number of supervisors as shown in TABLE 2 and 3. However, the span of control of the DP-designed structure (5.6) was higher compared to that (4.6) of the Heuristic-designed.

The reason for these differences is because DP algorithm, being an implicit enumeration, searches the entire solution space for the set of span of management which will result in the global optimum of each design problem. The Heuristic identifies an optimal solution for a stage (level) and uses it as input to next stage next (level). This might not lead to global optimum as is evident in the solution values corresponding to the DPdesigned structures being better than those of the Heuristic-designed (TABLE 2 and 3).

However, in terms of computation time, the implicit enumeration approach, the DP algorithm, takes more time than the Heuristic (TABLE 3 and Fig 2). It is clear from Fig. 2 that the DP algorithm time exhibits a degree-4 polynomial for lowest positions varying between 40 and 140 while the heuristic time displayed a quadratic curve for the same range (Fig. 3). At this range of operating positions, the DP algorithm is relatively efficient since the literature defines efficiency in terms of the degree of polynomial or exponential curves $[16,17]$. However, whether or not it is efficient, there is a consolation: the computation time is only in seconds ranging between 0.1 and 15.0. Hence, barring memory problems, for even large problems, organizational design with the DP algorithm may be feasible on Personal Computers. 


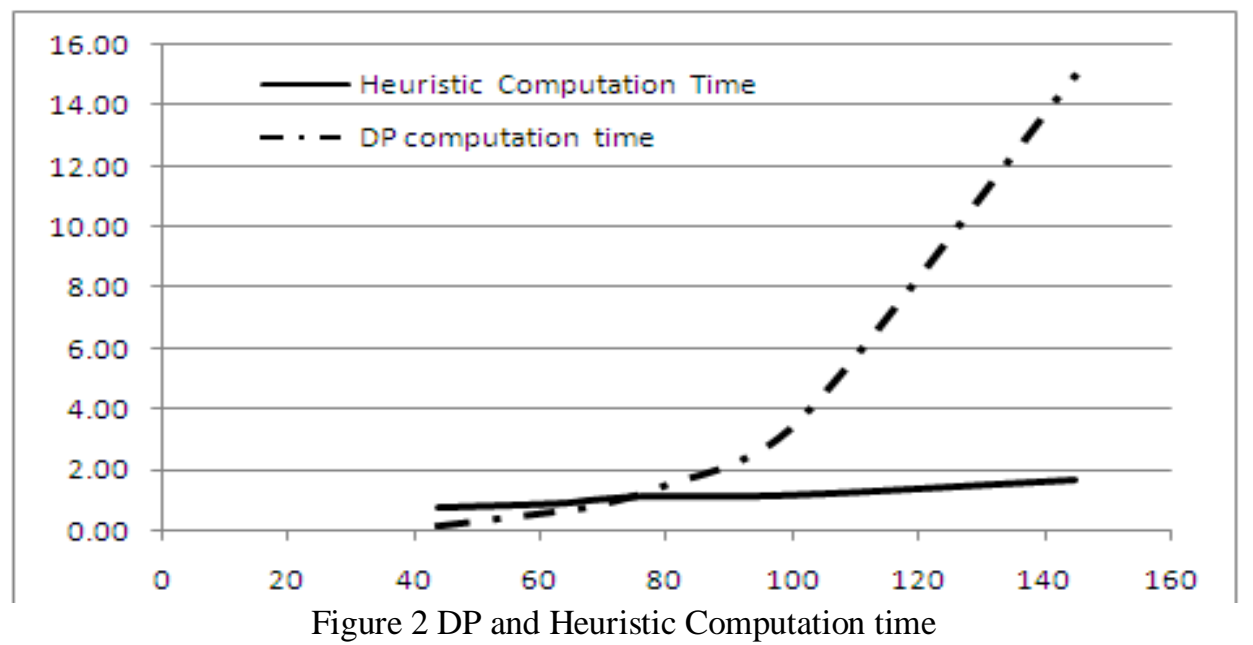

Relative to the existing structures of the cases examined, the DP designed algorithm substantially reduced the value of the number of management levels, number of managers and number of supervisors by $25 \%$, $70.6 \%$ and $17.2 \%$ respectively. The corresponding values for the heuristics were: $0 \%, 47.1 \%$ and $17.2 \%$ respectively.

\section{CONCLUSION}

The dynamic programming algorithm for designed organisational structures produced structures with higher personnel utilisation index and lower number of management levels, than structures designed using the existing heuristic. We can conclude that such organisational structure provides right amount of work at its positions and have less redundancies than those designed using the existing method.

By redesigning the existing organisation to achieve maximum personnel utilisation, the work force was reduced from 250 to 178 . This is cost saving.

The heuristic computational time was significantly lower than that of the dynamic programming algorithm. The computation times were generally less than 16 seconds.

\section{REFERENCES}

[1]. D. Miller, "Configuration of strategiy and structure: towards a synthesis," in Readings in Strategic Management, D. Asch, Ed. London: Macmillian, 1989.

[2]. O. E. Charles-Owaba, Organizational Design: A Quantitative Approach. Ugheli: Oputrum Books, 2002.

[3]. D. S. Cochran, "Impact of system design, organizational processes and leadership on manufacturing system design and implementation," in Proceedings of international CIRP design seminar--design in the new economy, , 2000.

[4]. Cochrann, D. S.,Kim, Y. and Kim. J. , "The impact of performance measurement on manufacturing system design.," in ICAD., Cambridgee, 2000b, pp. First Comference on Axiomatic Design. Cambridgee, MA: ICAD.

[5]. Cochran, D. S. and Chu, A. K., "Measuring manufacturing system design effectiveness based on the manufacturing system decomposition," in 27. Cochran, D. S. and Chu, A. K. 2000. Measuring manufacturing system design e Third World Congress on Intelligent Manufacturing Processes and Systems, Cambridge MA., 2000.

[6]. Robbins,S and Coulter, M. , "Organizational Structure and Design. ," in Management. New York: PrenticeHall, 2002, p. chapter 10.

[7]. J. Robert, Modern firm: organizational design for performance and growth, J. Robert, Ed. New York: Oxford University Press Inc., 2004.

[8]. Rivkin, J.W and Sigglekow N, "Balancing search and stability: interdependencies among elements of organisational design," Management Science, pp. 290 -311., 2003.

[9]. Hax A. C and Majluf N. S. , "Hax A. C Organizational Design: Survey and An Approach," Operational Research, vol. 29 , no. 3, pp. 417-447., 1981.

[10]. Horling, B and Lesser, V., "Quantitative Organizational model for large-scale Agent system.," in Proceedings of the inter-national workshop on massively multi-agent system, 2004, pp. 297-312.

[11]. H Mintzberg, "Organisational design: fa shion or fit.," Havard Business Review, pp. 103-116, 1981. 
[12]. O. E. Charles-Owaba, "On the Organizational structure Designs problem," Journal of Nigerian Institute of Industrial Engineers, vol. 1, no. 1, pp. 13-33, 1987.

[13]. Pfaffenberger, R. C and Walker, D. A., Mathematical Programming for Economis and Business. Iowa, The Iowa State, USA: University Press, 1976.

[14]. H. A. Taha, Operational Research: An introduction. New Jersey: Prentice Hall., 1986.

[15]. Hillier, F. S. and Lieberman, G. J., Introduction To Operations Research. New York: McGraw-Hill company, 2001.

[16]. Johnson, D S, Gutin G, McGeoch L A, Yeo A, Zhang W and Zverovitch A , "Experimental Analysis of Heuristics for tha Asymetric Traveling Salesman Problem," in The Traveling Salseman Problem and its Variations, G. Gutin and H. Punnen., Ed. Ac: Kluwer Ac, 2002.

[17]. Kwon, S Kin $\mathrm{H}$ and Kang M, "Determination of the candidate arc set for assymetric traveling salseman problem," Computer and Operations Research, vol. 32 , no. 5, pp. 1045-1057., 2005.

[18]. Ofiabulu, C. E. and Charles-Owaba, O. E., "A personnel cost model for Organisational structure Designs," Industrial Engineering Letters, vol. 3, no. 6, p. 1=11, 2013. 